\title{
Evolution of Behavior, Uncertainty, and the Difficulty of Predicting Labor Force Participation
}

\author{
Patrick Higgins \\ Federal Reserve Bank of Atlanta, USA
}

Julie L Hotchkiss

Federal Reserve Bank of Atlanta and Georgia State University, USA

E-mail: Julie.L.Hotchkiss@atl.frb.org

Ellyn Terry

Federal Reserve Bank of Atlanta, USA

Received: August 29, 2019 Accepted: September 28, 2019 Published: November 7, 2019

doi:10.5296/ber.v9i4.15350 URL: https://doi.org/10.5296/ber.v9i4.15350

\begin{abstract}
This paper demonstrates the difficulty of forecasting labor force participation (LFP) rates by showing that a random walk does just as well as select sophisticated econometric models in predicting short-term aggregate LFP. Most efforts to improve forecasts of LFP focus on fine-tuning predictions of determinants (i.e., demographics and labor market conditions). However, we show that even perfect knowledge of future demographic trends and labor market conditions is not enough to overcome the additional difficulty posed by changes in behavior over time. Behavior in this paper refers to the way in which demographics and labor market conditions impact labor supply decisions (i.e., parameter coefficients).
\end{abstract}

Keywords: Labor force participation, Labor supply, Random walk, Behavior, OASDI, EIA, Board of Governors

\section{Introduction}

Labor is an important input for most production processes. Therefore, changes in the share of the population willing and able to work is an important ingredient for economic growth. Labor force growth is also an important determinant for knowing how many jobs need to be created to achieve full employment (Hotchkiss, 2005). The importance of labor supply 
decisions' contribution to economic growth and in the achievement of full employment makes the task of forecasting them of particular interest to policy makers. For example, projecting labor force participation rates is an important part of the Congressional Budget Office (CBO) fulfilling its responsibility to produce forecasts of U.S. economic growth and in federal budget projections (Montes 2018). The staff of the Board of Governors of the Federal Reserve System regularly produces forecasts of labor force participation as an input into monetary policy deliberations about full employment. This paper demonstrates that forecasting labor force participation is not an easy task and identifies some sources of that difficulty. In particular, we illustrate that behavioral differences across demographic groups, changing trends within demographic groups, and behavioral uncertainty all contribute to the difficulty of forecasting labor force participation. We argue that consideration of these factors is at least as important as using accurate predictions about changing demographics and labor market conditions in forecasting labor force participation.

In the first section, we illustrate the difficulty of accurately anticipating changes in overall labor force participation by comparing prediction errors of the Board of Governors' staff forecast of labor force participation to that of a random walk. We show that a random walk performs at least as well. In the following section, we describe a typical strategy used to model the labor force participation rate (LFPR) and illustrate how in-sample prediction errors are improved when behavior (estimated parameters) is allowed to differ across broad demographic groups. Then, we compare out-of-sample forecast errors of the simple model with that of a random walk and the Board's forecast. We illustrate that good assumptions about the future values of regressors is very important for reducing forecast error. In the end, neither model complexity nor perfect foresight is able to improve upon a random walk.

\section{Forecasting Aggregate Labor Force Participation is "Hard"}

In a widely cited article, Stock and Watson (2007) show that after the onset of the "Great Moderation" in 1984, multivariate forecasting models of inflation, like a backwards looking Phillips Curve, were no longer more accurate than simple time-varying univariate forecasts such as the current 4-quarter inflation rate. Similarly, since the mid-1990s, a comparison of forecasts from a variety of sources against a naïve forecast (which simply takes the most recent value as the forecast), suggests that forecasting changes in the participation rate has been "hard" in the Stock and Watson (2007) sense over the past 20 to 25 years. In this section, we compare a representative sophisticated forecast of participation to a random walk.

The Federal Reserve Board staff (the Board) provides forecasts of the labor force participation rate to aid the Federal Open Market Committee (FOMC) in its policy deliberations. ${ }^{1}$ A number of studies that have investigated the quality of Board staff forecasts of macroeconomic variables have found them to be fairly accurate relative to other approaches. For example, using real-time data, Faust \& Wright (2009) found that the Board staff forecasts of inflation up to five quarters in the future were generally more accurate than

\footnotetext{
1 These forecasts were made available in the "Current Economic and Financial Conditions: Summary and Outlook" section of the Greenbook that was distributed to the FOMC prior to every meeting. The Tealbook, the name given to the Greenbook and the so-called Bluebook (officially entitled "Monetary Policy Alternatives") when they were merged together in June 2010, is released to the public with about a five-year lag.
} 
forecasts from a wide variety of a-theoretical macroeconometric models commonly used in the forecasting literature. Romer \& Romer (2000) found that the Board staff forecasts of inflation were superior to private commercial forecasts and Romer \& Romer (2008) found the staff inflation forecasts were also superior to those of the Federal Reserve Governors and Presidents in spite of the informational advantage of the latter. ${ }^{2}$ Other work evaluating more recent forecasts (e.g., Berge, Chang, \& Sinha, 2019; Reifschneider \& Tulip, 2019; and references cited in those papers) have found that the accuracy of the Board staff forecasts of inflation, GDP growth, and the unemployment rate has been comparable to and/or statistically indistinguishable from the consensus from private commercial forecasters.

Popular regular monthly and quarterly surveys of professional macroeconomic forecasters such as Blue Chip Economic Indicators, Consensus Forecasts, The Wall Street Journal Economic Forecasting Survey, and The Survey of Professional Forecasters do not include regular projections of the labor force participation rate. Perhaps that is one reason why the academic literature on evaluating out-of-sample labor force level or participation rate forecasts is quite sparse. ${ }^{3}$ Most of the related literature focuses on explaining the historical evolution of the LFPR and/or forecasting future labor force participation. ${ }^{4}$ In this section we restrict ourselves to comparing the Board staff forecasts to a random walk; Appendix 1 extends the analysis to the labor force projections of several other organizations.

The Board Staff LFPR forecasts from November 1996 through 2013 are publicly available and are often accompanied by analysis behind the LFPR projection. For example, the following text accompanies the forecast prepared for the September 2012 FOMC meeting:

"The labor force participation rate... fell 13/4 percentage points from the business cycle peak in the last quarter of 2007 through the second quarter of this year. The staff estimates that a little over 1 percentage point of this decline can be attributed to the long-term trend in participation. ... Looking ahead, the staff expects the cyclical downward pressure on labor force participation to diminish as the demand for labor improves, even as the long-term downtrend continues. In our projection these two forces are roughly offsetting in the medium term, and the participation rate remains fairly flat, converging slowly to its long-term trend."

In September 2012, the Board projected that the participation rate would remain at its latest

\footnotetext{
${ }^{2}$ Historically, the FOMC participants have submitted their forecasts after they have seen projections from the Board staff.

3 An example in this literature is Frees (2006) who evaluates out-of-sample time series model forecasts of both male and female LFPRs. D. Aaronson, Hu, Seifoddini, \& Sullivan (2014) compare their model's pseudo out-of-sample aggregate LFPR projections up to ten years in the future made during the 2002 to 2006 period with real-time 2002-2006 BLS projections and find that the model is much more successful in projecting the realized decline in participation through 2014.

${ }^{4}$ See, for example, D. Aaronson et al. (2014), S. Aaronson et al. (2014), S. Aaronson, Fallick, Figura, Pingle, \& Wascher (2006), Chalom, Karahan, Pilossoph, \& Topa (2018), Fujita (2014), Hornstein \& Kudlyak (2018), Hornstein, Kudlyak, \& Mullin (2019), Hornstein, Kudlyak, \& Schweinert (2018), Hotchkiss (2006, 2009), Krueger (2017), and Montes (2018). Additionally, Robertson (2019) and Terry (2019) utilize the Atlanta Fed's Labor Force Participation Dynamics tool available at https://www.frbatlanta.org/chcs/labor-force-participation-dynamics.aspx, which allows users to decompose the change in the LFPR over chosen time periods for selected demographic groups.
} 
reading of 63.7 percent through the end of 2014. As Figure 1 shows, the LFPR continued to fall through late 2013 before finally flattening out as the Board had envisioned.

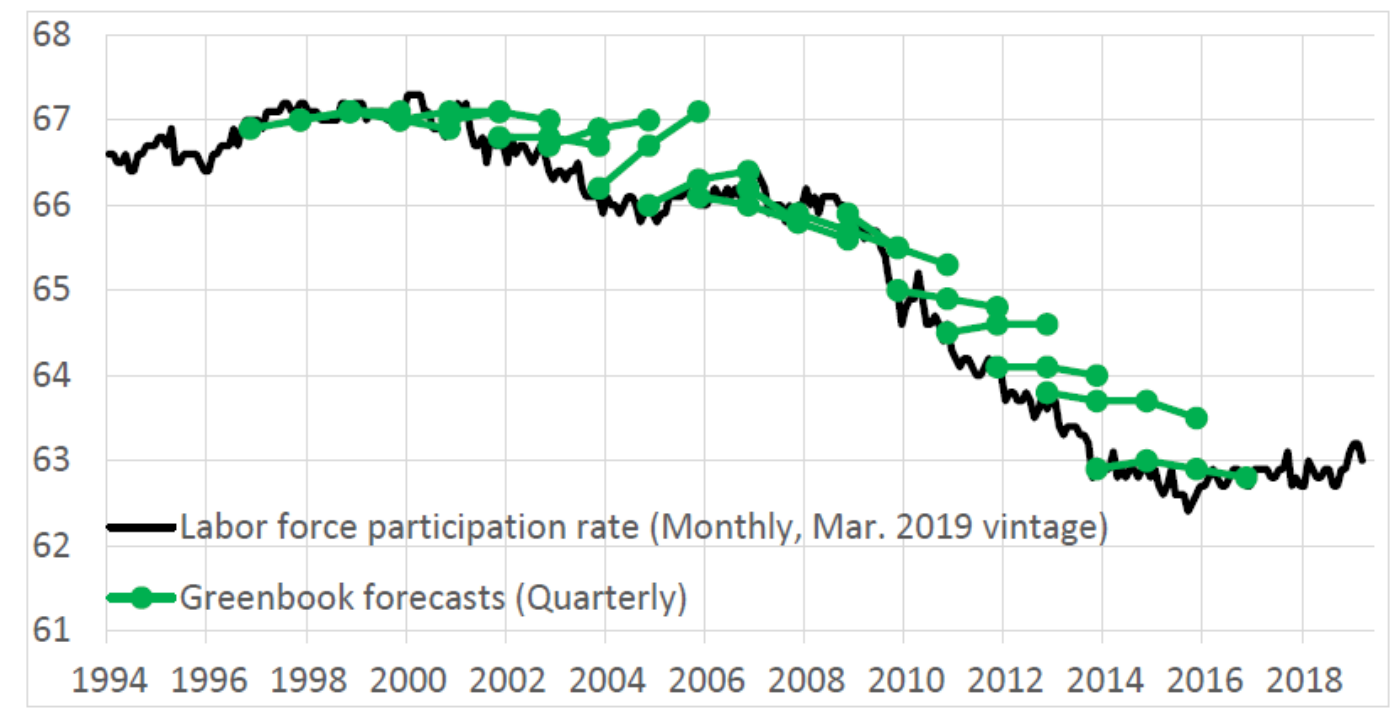

Figure 1. Actual and December Greenbook/Tealbook projections of labor force participation rate (percentage points, seasonally adjusted)

The Board's staff LFPR forecast has often, but not always, resembled an unchanged, or "random walk" forecast. A time that it deviated from the random walk tendency occurred in a September 2003 forecast in which the Board stated, "that improving conditions in labor markets ... [would] induce a substantial rebound in the participation rate," in the following year. However, the nearly one percentage point rebound in the LFPR to about 67 percent in the fourth quarter of 2005 did not materialize, as Figure 1 shows. Instead, the LFPR was about 66 percent at the end 2005, very close to what a random walk forecast would have projected in late 2003. Although the Board staff has consulted models when forecasting labor force participation, they have not always directly incorporated their model results into their official projections provided to the FOMC. ${ }^{5}$

Has the random walk forecast of the LFPR been more or less accurate, on average, over time than more sophisticated forecasts? Table 1 compares the root-mean square forecast error (RMSFE) of 4-quarter and 8-quarter ahead projections of the fourth quarter LFPR from each year's December Board forecast from 1996 to 2013 with the RMSFE of the random walk forecast of the LFPR over the same sample period and forecast horizons. The random walk forecast maintains the labor force participation rate at its latest monthly value available at the date of the corresponding forecast from the Board. Table 1 shows that the RMSFEs of the Board's and random walk forecasts of the LFPR are very similar. The Diebold and Mariano (1995) (DM) test statistic does not indicate statistically significant differences in the accuracy of the competing forecasts at either the 4-quarter or 8-quarter forecast horizon or when either

\footnotetext{
5 For example, S. Aaronson, Fallick, Fleischman, \& Tetlow (2013, p. 6) state that "the staff's model of labor force participation has, for some time, shown a lower level of, and steeper decline in, trend labor force participation than was built into the April Tealbook projection. Note, however, that several other estimates of the trend participation rate suggest a higher trend than we have assumed."
} 
first-release or March 2019 vintages of the labor force participation rate are used to evaluate forecast accuracy. Appendix A compares the performance of other sophisticated forecasts for labor force growth, the analogue to forecasting LFP, with a random walk forecast adjusted for expected population growth and comes to the same conclusion as seen in Table 1.

Table 1. Root-mean square forecast errors of fourth quarter labor force participation rate (percentage points), Board of Governor's model vs. a random walk forecast

\begin{tabular}{|l|l|l|l|l|}
\hline & \multicolumn{2}{|l|}{$\begin{array}{l}\text { Errors determined with March } \\
\text { 2019 vintage LFPR data }\end{array}$} & \multicolumn{2}{l|}{$\begin{array}{l}\text { Errors determined with first } \\
\text { published values }\end{array}$} \\
\hline & 4-qtr ahead & 8-qtr ahead & 4-qtr ahead & 8-qtr ahead \\
\hline Greenbook forecast & 0.45 & 0.66 & 0.43 & 0.65 \\
\hline Random walk forecast & 0.41 & 0.68 & 0.41 & 0.68 \\
\hline
\end{tabular}

Notes: Greenbook 4-quarter and 8-quarter ahead LFPR forecasts are taken from December Greenbook/Tealbook of each year 1996-2013. Random walk forecasts are taken from the last (seasonally adjusted) monthly value from most recently released employment report available by the December Greenbook/Tealbook release of each year. The primary difference between first-published and vintage estimates of monthly/quarterly LFPR is due to revision of seasonal adjustment factors. Occasionally, there are revisions due to decennial Census population controls.

Conclusions from the horse race reported in Table 1 suggest that forecasting the labor force participation rate has been "hard" in the Stock and Watson (2007) sense, since at least the mid-1990s. The rest of the paper illustrates how the evolution of behavior and behavioral uncertainty contributes to that difficulty.

\section{A Model of Individual Labor Force Participation}

In addition to official government agency forecasts of the aggregate labor force participation rate (LFPR), there are a number of forecasts offered on a less regular basis by economists (Aaronson et al., 2014; Hornstein and Kudlyak 2018; Aaronson et al., 2014; Hornstein, Kudlyak, and Schweinert, 2018). The methodology used by each of the sources above (including the Board's) is broadly similar, however they differ in details related to demographic and economic determinants of participation decisions and modeling complexity. For example, in producing their forecasts, the CBO estimates separate models for 516 age/sex/education/race subgroups (Montes, 2018). Additionally, several authors use different determinants (regressors) for LFP depending on the age group (Aaronson et al., 2014). ${ }^{6}$

Generally, however, the process is to estimate a model of participation for a number of unique demographic groups, differentiated based on characteristics such as age, sex, education, race/ethnicity, birth year, etc. ${ }^{7}$ Economic or business cycle determinants of labor supply

\footnotetext{
${ }^{6}$ While the Board of Governor's forecasting methodology is not made public, it likely follows the most common methodologies found in the literature.

7 Distinction between groups by birth year, or cohort, is based on the assumption that individuals are born with a tendency for labor force participation that follows them throughout their life. However, birth year is not enough to explain changing behavior over time because it does not control for time-variant shocks such as a
} 
decisions typically include measures such as the unemployment rate or unemployment gap and some measure of potential wages. Once the determinants of participation are estimated within each of the demographic groups for a specific time period in the past, the group LFPRs, or their trends, are aggregated using weights based on projected group population shares. ${ }^{8}$ As evidence for the merit of this approach, S. Aaronson et al. (2014) noted that the S. Aaronson, Fallick, Figura, Pingle, \& Wascher (2006) model projection of the trend LFPR in 2014 was very close to its realized value. ${ }^{9}$

\subsection{The Importance of Differences across Demographic Groups; In-sample Predictions}

To illustrate the importance of allowing participation behavior to differ across demographic groups, we estimate a simple empirical model of individual participation. Specifically, the following linear probability model is estimated separately for four demographic groups: 16-24 year-olds, 25-54 year old men, 25-54 year old women and 55+ year-olds via Ordinary Least Squares (OLS). The model takes the form:

$$
L F P_{i s t}=f\left(X_{i s t}, L M_{s t}\right)+\varepsilon_{i s t}
$$

where $L F P_{i s t}$ is equal to one if person $i$ in state $s$ at time $t$ is in the labor force, zero otherwise; $X_{\text {ist }}$ are individual level characteristics that have been shown in the economics literature to impact a person's reservation wage (age, sex, number of children, marital status, education, race/ethnicity, and birth cohort); and $L M_{s t}$ are measures of relative labor market strength that will influence the market value of the person's time (state-specific unemployment rate gap and education/sex/state specific median wage). ${ }^{10}$ Each individual's comparison of their reservation wage (the value of non-market time) and their market wage (the value of being in the labor market) determines their labor supply decision.

The primary difference between our model and those of others is that equation (1) is estimated at the individual level and then aggregated, whereas it is common in the literature to aggregate based on demographic characteristics, then estimate determinants of labor force participation rates for the group. Therefore, we are estimating the average of determinants of

policy change (e.g. change retirement age for Social Security eligibility) or economic shocks that also affect labor supply decisions. In light of this, some models (such as D. Aaronson et al., 2014; S. Aaronson et al., 2006) allow for the cohort effect to change over time.

${ }^{8}$ Hornstein, Kudlyak, and Schweinert (2018) differ somewhat in that they do not rely on structural regressors, but simply aggregate different trends across demographic groups.

9 Trend LFPR in their paper is the model's predicted participation rate purged of all cyclical influences. Specifically, the S. Aaronson et al. (2006) projections of a trend LFPR of 62.9 percent in 2014 and 62.5 percent in 2015 were identical or close to the realized values of 62.9 percent in 2014 and 62.7 percent in 2015. By comparison, the 2014-15 LFPR projections of the CBO, BLS, and SSA made around the same time were 65.0 percent or higher.

${ }^{10}$ Following Hotchkiss \& Moore (2018), the state specific unemployment rate gap in quarter $q$ is constructed as follows:

$U R \operatorname{Rap}_{s q}=U R_{S q}-\left[L T U R_{U S, q}+\left(U R_{S, 8018}-U R_{U S, 8018}\right)\right]$, where $U R_{S, 8018}$ is the average unemployment rate in state $s$ over the period 1980-2018, $U R_{U S, 8018}$ is the average unemployment rate over the same time period in the whole U.S., $U R_{S q}$ is the actual quarterly unemployment rate in state $s$ in quarter $q$, and $L T U R_{U S, q}$ is the Congressional Budget Office determined long-term unemployment rate for the U.S. (see https://www.cbo.gov/about/products/budget-economic-data\#6). A three-year rolling average of the gap is used as it is assumed that individuals take more than just the current year's economic condition into account when making labor supply decisions. 


\section{Macrothink}

Business and Economic Research

ISSN 2162-4860

2019, Vol. 9, No. 4

LFP rather than the determinants of average LFP. Another difference from more complex models is that we are estimating separate models for only four different age groups and using the same regressors for all groups.

We make use of monthly Current Population Survey (CPS) data to estimate the model of individual labor force participation. The CPS is administered to roughly 60,000 households each month by the U.S. Census Bureau for the Bureau of Labor Statistics. This is the nationally representative cross-sectional survey from which we get national reports of the unemployment rate and the labor force participation rate, among other monthly labor market statistics.

Fitting the model for each of the four demographic groups using monthly CPS data between 1982 and 2018 produces a predicted LFPR for each group, as shown in Figure 2. Merely from visual inspection, it's clear that the model produces more accurate LFPR estimates for some demographic groups than for others. The in-sample root-mean-squared-error (RMSE) (found in notes to figures) for 16-24 year-olds and prime age women is higher than that for prime age men or the $55+$ age group. ${ }^{11}$

(a) Youth, 16-24

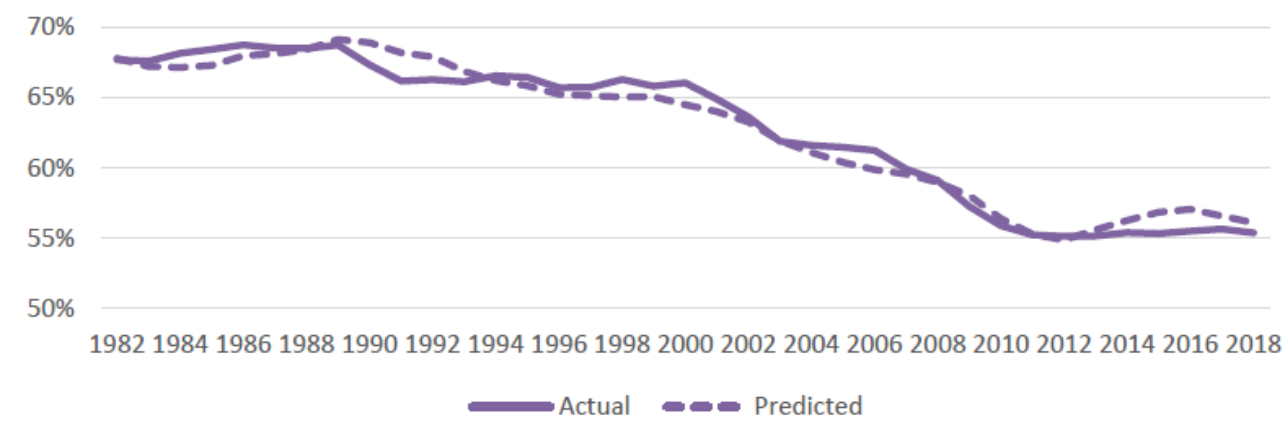

(b) Prime age men and women, 25-54

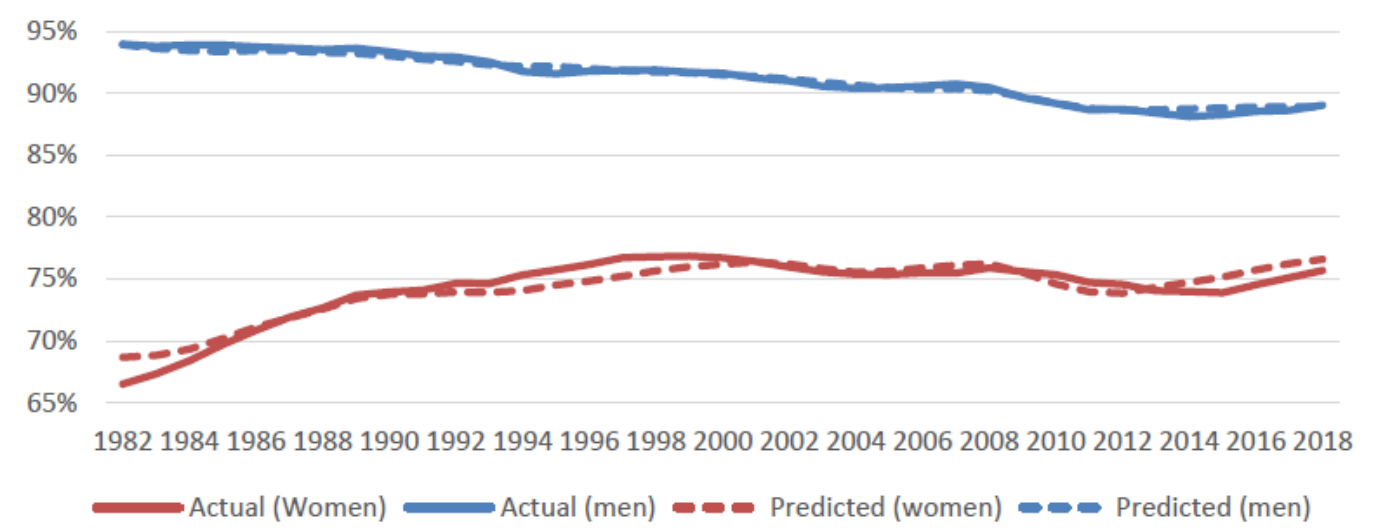

\footnotetext{
11 Based on a standard t test statistic, the MSE for youth and prime age women is statistically significantly different from the MSE for prime age men at least at the 99 percent confidence level. The MSE for the youth is statistically significantly different from the MSE of the elderly at the 90 percent confidence level.
} 
(c) Older, 55+

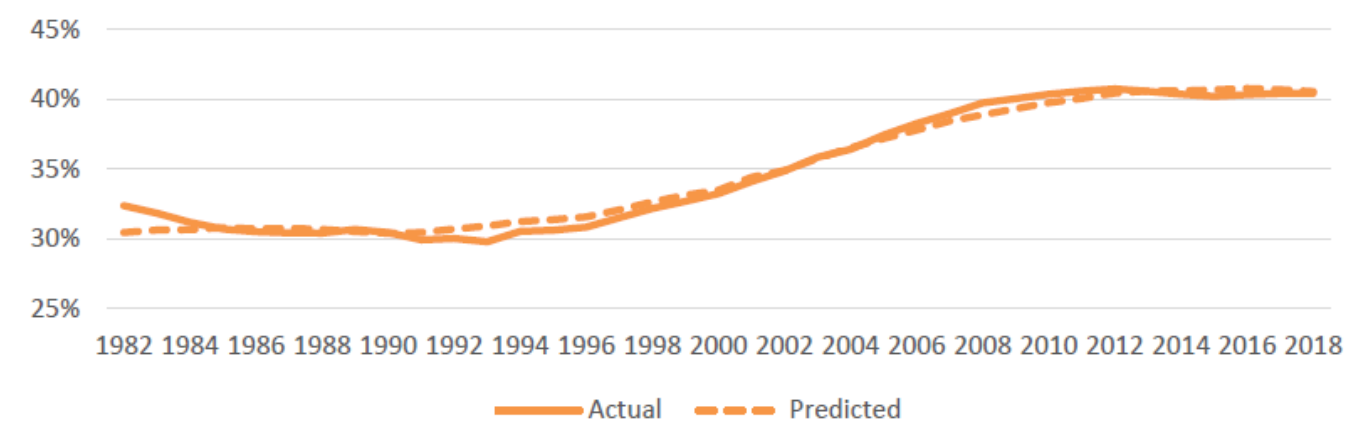

Figure 2. Actual and predicted LFP rates by demographic group, 1982-2018.

Notes: In-sample RMSEs are: 0.87 for youth, 0.85 for prime age women, 0.30 for prime age men, 0.60 for $55+$.

Weighting each of these four estimated group participation rates by their population shares produces the aggregate fitted participation rate for the population as a whole. This is shown by the dashed line in Figure 3. Figure 3 also shows in-sample fitted values for labor force participation when the model is not estimated separately for the four groups (see the dotted line). That is, a pooled model that assumes the impact of individual characteristics and labor market conditions on the participation decision is the same for each of the four demographic groups.

The in-sample RMSE for the pooled model is 0.47, compared to the RMSE corresponding to the weighted predictions for each demographic group separately of 0.31 . In particular, the better model fit for prime age men and those aged 55+ improves the overall fit. Note that neither model does particularly well in capturing the change in aggregate LFP between 2013 and 2018. The weighted estimate also performs about the same as does a random walk estimate of aggregate LFP, which yields an in-sample RMSE of 0.33.

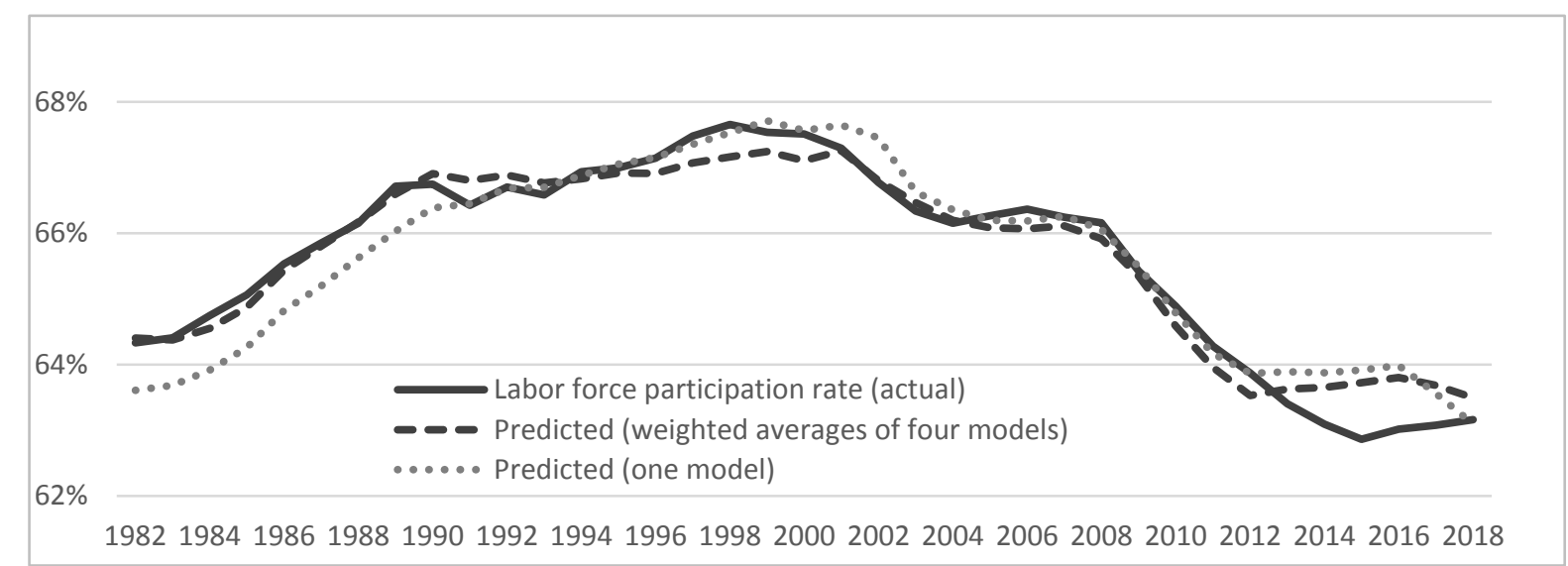

Figure 3. Aggregate Actual and Predicted Aggregate LFP Rates, 1982-2018.

Notes: In-sample RMSE assuming the aggregate LFPR follows a random walk is 0.33 , for the weighted LFPRs across demographic groups is 0.32 , and for the prediction combing all four groups for the estimation is 0.47 . 
Fitting separate models by demographic group performs better than one that combines the demographic groups because behavior differs and has changed differently over time across the four groups. In general, estimating the pooled model assumes that each of the demographic elements not controlled for in the model and each of the economic determinants impact the labor supply decision in the same way over time and is the same for each group; this may or may not be an appropriate assumption. Section IV will illustrate the implication of this assumption explicitly.

\subsection{Using the Model to Forecast Out-of-sample}

This section compares the out-of-sample forecast performance of models of varying complexity. Specifically, Table 2 compares the root mean square forecast error (RMSFE) for one- and two-year ahead forecasts for the Greenbook forecast described in Section 1, the random walk forecast, and three forecasts based on estimating equation (1) for each demographic group. Using data back to 1982, the equation (1) model forecasts (a-c) combine all years of data through year $t$ to create forecasts of LFPR in year $t+1$ and $t+2$. Each model forecast (a-c) differs in what is assumed about the out of sample values of the model's regressors.

The "perfect foresight" forecast (a) uses the actual values for each of the regressors in years $t+1$ and $t+2$ in order to make the forecast. Forecasts (b) and (c) project age and birth cohort shares using vintage Census projections, use a three year trend (the average change from $\mathrm{t}-3$ to $t$ is projected forward) to project all other demographics (e.g., race and education shares, marital status, number of children), and sets median wages equal to their forecast year values. The difference between (b) and (c) is that forecast (b) sets the unemployment gap at its forecast year value, while (c) uses the Blue Chip Economic Indicators forecast of the unemployment rate gap, since professional forecasters have been shown to produce more accurate unemployment rate forecasts. ${ }^{12}$

Table 2. Root-mean square forecast errors (RMSFE) across different estimating models.

\begin{tabular}{|c|c|c|c|c|}
\hline & \multicolumn{2}{|c|}{$1996-2013$} & \multicolumn{2}{|c|}{ 1996-2018 } \\
\hline & $\begin{array}{l}\text { One year } \\
\text { ahead }\end{array}$ & $\begin{array}{l}\text { two years } \\
\text { ahead }\end{array}$ & $\begin{array}{l}\text { one year } \\
\text { ahead }\end{array}$ & $\begin{array}{l}\text { two years } \\
\text { ahead }\end{array}$ \\
\hline Greenbook forecast & 0.45 & 0.66 & -- & -- \\
\hline Random walk forecast & 0.36 & 0.67 & 0.33 & 0.62 \\
\hline Equation (1) forecasts & & & & \\
\hline (a) perfect foresight for all variables & 0.36 & 0.44 & 0.52 & 0.61 \\
\hline $\begin{array}{l}\text { (b) projecting demographics and forecast year for } \\
\text { median wage \& unemployment rate gap }\end{array}$ & $0.45 * *$ & 0.68 & $0.51 * *$ & 0.67 \\
\hline $\begin{array}{l}\text { (c) projecting demographics and forecast year } \\
\text { for median wage; Blue Chip forecast for u-rate gap }\end{array}$ & 0.36 & 0.55 & 0.53 & 0.65 \\
\hline
\end{tabular}

Notes: See notes to Table 1 for source of Greenbook forecast. The random walk forecasts in this table differ from those reported in Table 1 since these estimates make use of annual averages of monthly LFPR estimated

${ }^{12}$ For example, Stark (2010) showed that zero- to four-quarter ahead consensus forecasts of the unemployment rate from the Survey of Professional Forecasters were each significantly more accurate at the 5 percent level than a random walk forecast over the 1985-2007 period, with RMSFEs between 20 and 45 percent smaller. 
using the Current Population Survey. The in-sample forecast model (equation 1) uses all data available up to and including the current year (using data back to 1982) and constructs an aggregate LFPR from a weighted average of estimating the model separately for four different demographic groups (16-24 year-olds, prime age women, prime age men, and 55+ year-olds). Age and cohort shares are projected using vintage Census projections (https://www.census.gov/programs-surveys/popproj/library/publications.html). All other demographics (e.g., race and education shares, marital status, number of children) are projected for $t+\mathrm{j}(\mathrm{j}=1,2)$ from a trend using three years of data (the average change from $t-3$ to $t$ is projected forward), and median wage is simply its value at time t. ** indicates forecast is different from a random walk at the 95 percent confidence level, using the Diebold and Mariano (1995) test of forecast accuracy. None of the forecasts in columns one and two is statistically different from the Greenbook forecast, based on the Diebold and Mariano (1995) test statistic.

Focusing first on the 1996-2013 time period when the Greenbook forecasts are available, we see that none of the approaches does statistically significantly better than a random walk. ${ }^{13}$ Comparing each of the equation (1) model based forecasts, it is clear that knowing the future values of the regressors (or at least having a well-informed guess) helps the forecast, as forecasts (a) and (c) consistently produce lower RMSFEs in the 1996-2013 time period, than just using the forecast year value for the unemployment rate (forecast $b$ ). And, given that forecast (a) out-performs the Greenbook forecast, the implication is that knowing the future (i.e., perfect foresight) is at least as important as complexity in modeling the past.

Turning now to the out-of-sample RMSFE statistics for the 1996-2018 period in Table 2, we see that forecast accuracy can also depend on the time period over which the forecast is made. The random walk model performs similarly to the earlier time period, but the performances of both the perfect foresight and the Blue Chip forecasts are worse when the years 2014-2018 are included in the analysis. This is because the overall participation rate continued to fall through 2015 in spite of the improvement in the labor market. As can be seen in Figure 3, the estimated models predicted an increase (or at least an earlier flattening) of LFP in response to the dramatic improvements in the labor market that did not come to fruition. This brings us to the difficulty in predicting behavioral responses.

\section{Evolution of Behavior and Uncertainty}

So far, we have seen that forecasts from the representative model are influenced by whether coefficients are assumed constant over different demographic groups and by the quality of the future predictions of exogenous variables. A third important factor is whether the coefficients are stable over time. For example, while women are less likely to participate in the labor force than men, the "impact" of being female on the decision underwent a dramatic change during the latter half of the 20th century. Estimating one set of parameters across time amounts to essentially averaging the response of LFP to changes in demographics and labor

\footnotetext{
13 Note that even though the difference between the RMSFE of the random walk and forecasts (a) and (c) are smaller, the loss differentials in the terminology of the DM test statistics, are larger than the RMSFE difference between the random walk and forecast (b), the standard deviation of the loss differential in the forecast (a) and (c) comparisons is nearly double the standard deviation of the loss differential comparing the random walk with forecast (b).
} 


\section{Macrothink}

Business and Economic Research

ISSN 2162-4860

2019, Vol. 9, No. 4

market conditions over the entire time period; this may not accurately reflect behavioral trends. $^{14}$

To illustrate the degree of influence changing behavior over time might have in the ability to forecast labor supply decisions, we re-estimate equation (1) separately for each year of data -allowing full interaction of behavior and time. Figures 4 and 5 illustrate the implication of allowing behavior to vary over time for the model estimated among prime-age men and women. Analogous figures for 16-24 year-olds and those age 55+ can be found in Appendix 2 .

Some behavioral responses associated with certain factors have changed over time more than others. For example, the coefficient on marriage among prime-age men is relatively stable over time, with no apparent trend. However, the negative impact of marriage on the labor supply of prime-age women decreased significantly until the mid-1990s and has since not changed much. Additionally, whereas marriage has a solidly positive impact on the labor force participation decisions of men, it decreases women's labor force participation; this is one reason why aggregate LFPR predictions using separate group estimates are likely to dominate predictions from estimations that combine the groups.
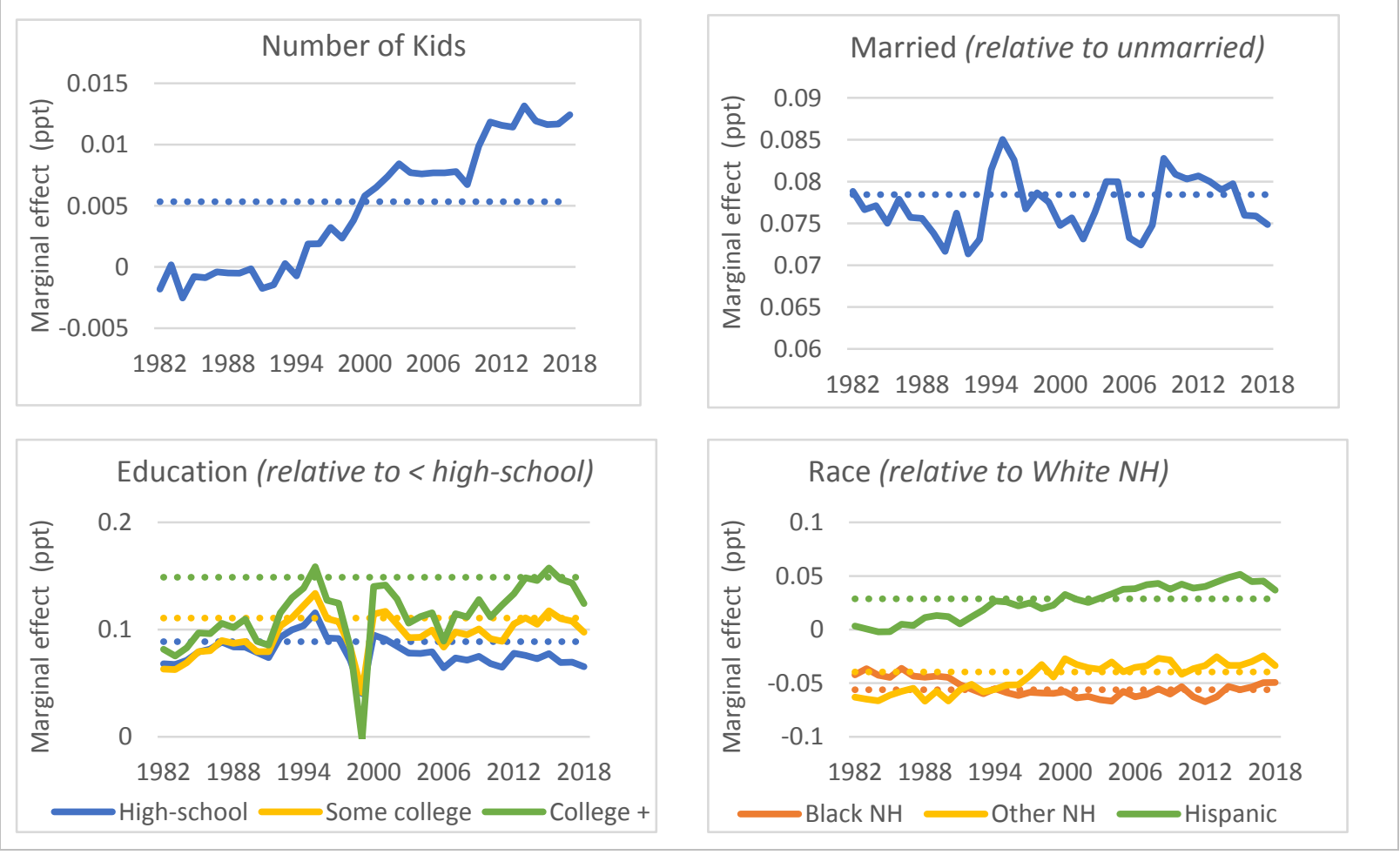

${ }^{14}$ Others (Aaronson et al., 2014) do allow some determinants to change over time. 

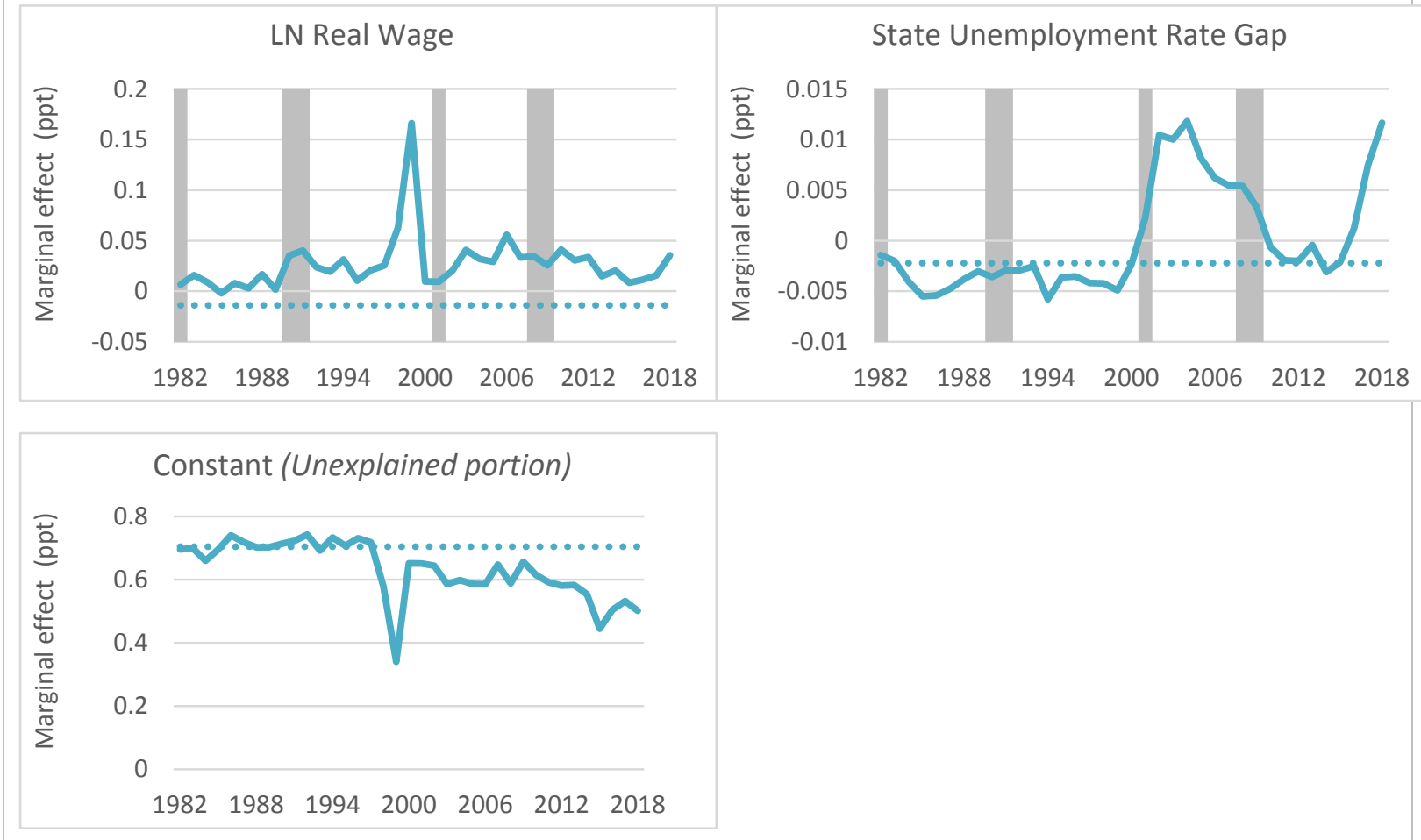

Figure 4. Coefficients estimated each year versus all years together, prime-age men

Notes: Dotted lines are coefficients estimated using data between 1982 and 2018 together. Solid lines reflect coefficients for model estimated on single years of data. Coefficients for age and age squared are not shown.

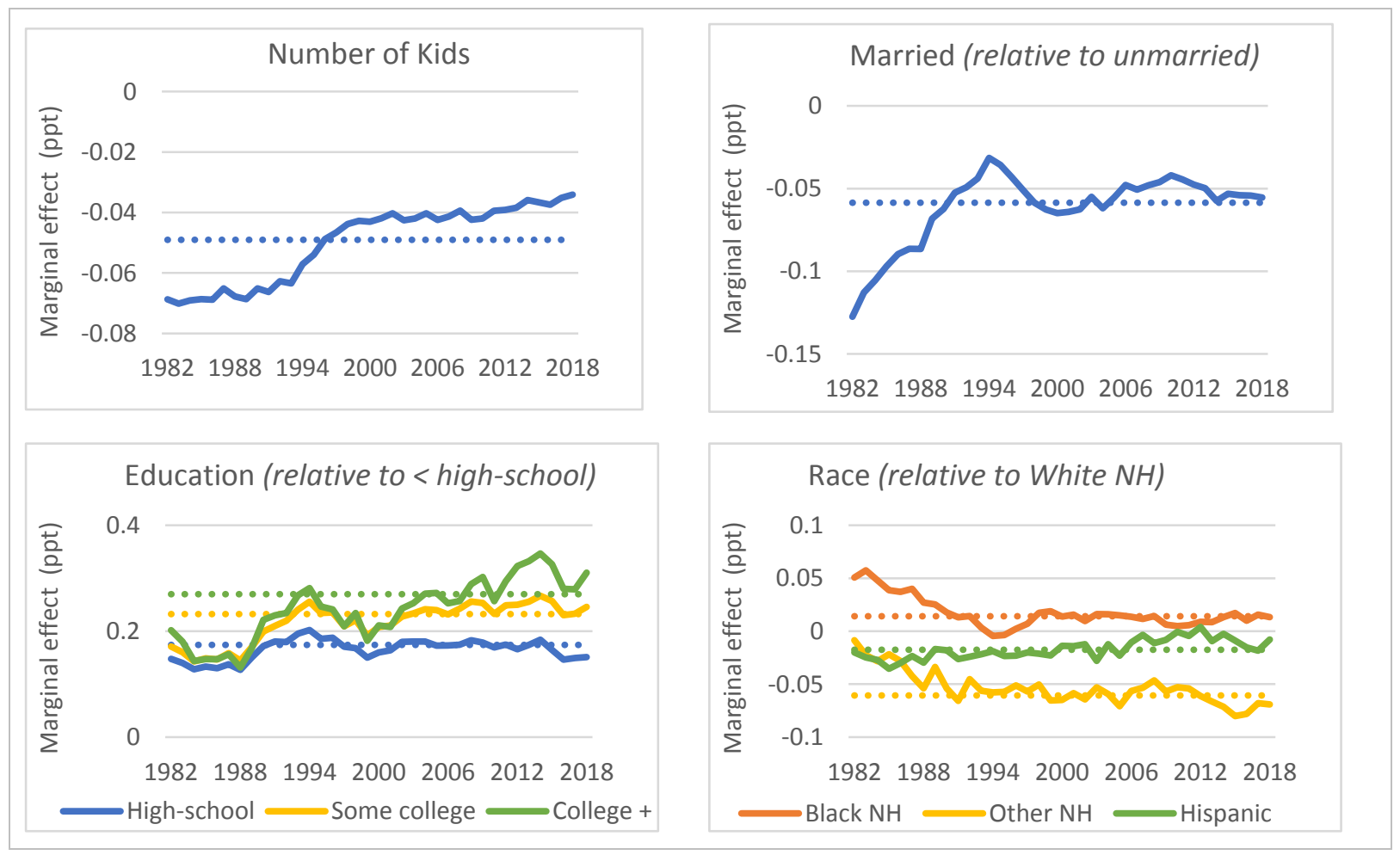




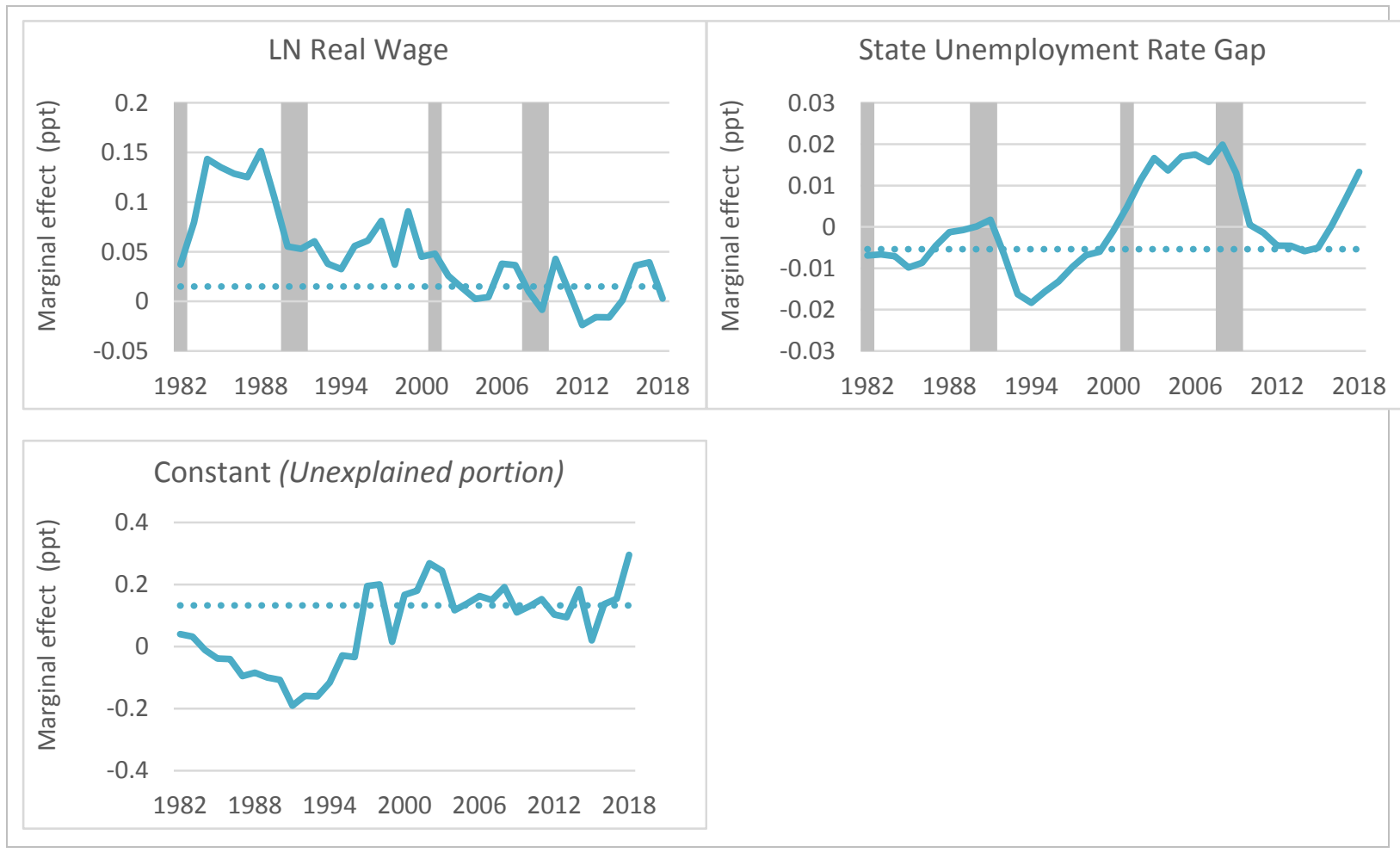

Figure 5. Coefficients estimated each year versus all years together, prime-age women

Notes: Dotted lines are coefficients estimated using all data between 1982 and 2018. Solid lines reflect coefficients for model estimated on single years of data. Coefficients for age and age squared are not shown.

Regarding the impact of labor market conditions on labor supply decisions, the responsiveness of prime-age men to changes in wages has been fairly stable. ${ }^{15}$ However, labor force participation of women has become less sensitive to changes in wages. This is consistent with shrinking labor supply elasticities documented by Blau and Kahn (2007). It also appears that while there is little difference in the impact of wages on labor supply decisions across the business cycle, this is not the case for the impact of the unemployment rate gap. Generally, the responsiveness of LFP to changes in the unemployment rate gap for all demographic groups was relatively dramatically positive during the expansion of the 2000s, fell during and after the Great Recession, and is, again, on the rise. It appears as though a strong labor market (at least recently) produces a negative added-worker effect -when the economy is doing well, other sources of income (e.g., spouse, non-labor income) are performing well, apparently discouraging participation. On net, however, the relationship between a higher unemployment rate gap (weaker labor markets) and LFP is mostly negative.

The RMSFE in Table 2 for model (c) illustrates how important it is to know, or at least have a

\footnotetext{
15 There is a spike in parameter estimates in 1999 for prime age men in education, median wage, and the constant term; and parameter estimates in 1984 and 2003 for youth in education, female, median wage, and the constant term. These spikes result from correlation between education and the age/sex/state-specific median wage; the spike in median wage and the constant disappear when education is excluded from the regression. Also, excluding these years from the analyses in this paper (results available upon request) does not change the conclusions.
} 
good guess about, future values of the data, especially labor market conditions. In order to quantify the importance of accurately representing future behavior, we calculated the RMSFE of model (c) using perfect foresight for behavior. ${ }^{16}$ The results are reported in Table 3. For the 1996-2013 forecast period there is no significant gain to using the estimated coefficients for the forecast years. However, when the 2014-2018 period is considered, when both behavior and labor market conditions are changing dramatically, knowing coefficients produces a statistically significant improvement in forecast accuracy. The improvement is less pronounced at the two-year horizon where there is more uncertainty about demographics and labor market conditions relative to the one-year horizon.

Table 3. RMSFE for model (c) in Table 2 with different assumptions about behavior

\begin{tabular}{|l|l|l|l|l|}
\hline & \multicolumn{1}{|c|}{$\begin{array}{l}\text { 1996-2013 } \\
\text { two years } \\
\text { ahead }\end{array}$} & $\begin{array}{l}\text { one } \\
\text { year } \\
\text { ahead } \\
\text { ahead }\end{array}$ & $\begin{array}{l}\text { two } \\
\text { years } \\
\text { ahead }\end{array}$ \\
\hline RMSFE, model (c) from Table 3 & 0.36 & 0.55 & 0.53 & 0.65 \\
\hline $\begin{array}{l}\text { (assuming behavior will be equal to that estimated between } \\
1982 \text { through forecast year) }\end{array}$ & & & \\
\hline RMSFE, model (c) with perfect foresight for behavior & 0.36 & 0.59 & $0.33^{* *}$ & $0.54^{\wedge}$ \\
\hline $\begin{array}{l}\text { (using parameter estimates using data from t+1 and } t+2 \text { to } \\
\text { forecast behavior in } t+1 \text { and } t+2, \text { respectively) }\end{array}$ & & & \\
\hline
\end{tabular}

Notes: See notes to Table 2. Notably, age and cohort shares are projected using vintage Census projections. All other demographics (e.g., race and education shares, marital status, number of children) are projected for $\mathrm{t}+\mathrm{j}$ $(j=1,2)$ from a trend using three years of data (the average change from $t-3$ to $t$ is projected forward), median wage is simply its value at time $t$, and the unemployment rate gap is the Blue Chip forecast. ** $(\wedge)$ indicates the RMSFEs from the two forecasting assumptions are statistically different from one another at the 95 (89) percent confidence level, based on the Diebold and Mariano (1995) test of forecast accuracy.

Additionally, there are a significant number of unobserved determinants of labor supply decisions whose influence is estimated only collectively through the intercept term in the model, and this also could vary considerably over time. The last chart in Figures 4 and 5 illustrate the degree to which these unobserved factors (from the perspective of the estimated model) varies over time. Recently, the contribution of unobservables to LFP decisions for prime-age men are falling (moving toward zero, albeit very slowly), whereas the contribution of unobservables for prime-age women has been relatively stable.

\section{Conclusion}

Forecasting labor force participation is not straightforward and, like many macroeconomic variables, a random walk forecast sets a benchmark that is difficult to beat. This paper has demonstrated that forecasts from a more sophisticated model of labor force participation, such as that produced by the staff of the Board of Governors of the Federal Reserve System,

\footnotetext{
16 This essentially amounts to projecting demographics and labor market conditions in year $t$, but using the parameter coefficients obtained from estimating the model with one year's worth of data in each of years $t+1$ and $t+2$ in order to generate the $t+1$ and $t+2$ forecasts.
} 
has difficulty beating a random walk. Additionally, the relatively more simple model estimated here does just about as well, based on a comparison of root mean square forecast errors.

This paper highlights why it is difficult to beat a random walk. In fact, the methods used here can be used by researchers considering employing similar strategies. For example, if a forecaster wishes to predict a future outcome variable using the average estimated behavior in the past, they should first consider testing to see if the estimated effect of such behavior, as measured by the model (the coefficients on the regressors), has changed over time. If there is significant time-variation in the coefficients, this suggests that past behavior may not be a particularly accurate predictor of the future.

Second, a time-varying constant term from the regression (or, the unexplained portion of the model) also makes it difficult to predict the future -- the model can't predict what it can't anticipate. As is often the case in trying to predict labor supply behavior, the unexplained portion in our model is not only time-varying, but is also relatively large in terms of the marginal effect on participation decisions, compared to other variables in the model.

Last, even if the model is well-specified in that past behavior is a good indicator of future behavior and if the unexplained portion of the model is relatively stable over time, accurate predictions of the outcome variable additionally require good estimates of the future values of the variables used the model. In the case of our LFP model, this includes the future demographic trends and labor market conditions.

When predicting LFP, even perfect knowledge of future demographic trends and labor market conditions was not enough to overcome errors stemming from changes in behavior over time. Such changes in behavior will continue to pose challenges to forecasting aggregate labor force participation, suggesting a need for LFP forecast models to incorporate these time-varying behavior effects for more regressors than are typically considered.

One feature of the CPS microdata that this study has not exploited is the ability to longitudinally match person-level observations in the dataset up to 15 months apart. ${ }^{17}$ BLS data on labor force status flows from the CPS since 1990 show that between 95 and 97 percent of persons in the labor force remain in the labor force in the following month. ${ }^{18}$ So using the current labor force status variable within our framework to predict one-year ahead labor force participation may improve forecasting power subject to some technical adjustments. ${ }^{19}$ We leave this approach to future research.

\section{Acknowledgement}

The views expressed here do not reflect those of the Federal Reserve Bank of Atlanta or the Federal Reserve System. Appreciation is extended to Brent Meyer and John Robertson for

\footnotetext{
17 Longitudinally matched CPS data can be accessed at https://www.kansascityfed.org/research/kcdc/cps.

18 See https://www.bls.gov/cps/cps_flows.htm.

19 For example, Coglianese (2018) shows that the labor force participation rate of prime-age males whose responses can be matched across all 8 months they can be in the CPS sample have a participation rate between 1 and 2 percentage points than the total LFPR for prime age LFPR. However, one-year changes in the matched and total prime-age male LFPRs closely resemble each other.
} 
helpful comments and suggestions.

\section{References}

Aaronson, D., Hu, L., Seifoddini, A., \& Sullivan, D. G. (2014). Declining Labor Force Participation and Its Implications for Unemployment and Employment Growth. [Online] Available: https://papers.ssrn.com/abstract=2598524

Aaronson, S., Cajner, T., Fallick, B., Galbis-Reig, F., Smith, C. L., \& Wascher, W. (2014). Labor Force Participation: Recent Developments and Future Prospects. Brookings Papers on Economic Activity, 45(2), 197-275. https://doi.org/10.1353/eca.2014.0015

Aaronson, S., Fallick, B., Figura, A., Pingle, J., \& Wascher, W. (2006). The Recent Decline in the Labor Force Participation Rate and Its Implications for Potential Labor Supply. Brookings Papers on Economic Activity, 1, 69-154. https://doi.org/10.1353/eca.2006.0012

Aaronson, S., Fallick, B., Fleischman, C., \& Tetlow, R. (2013). Assessing the Recent Decline in the Unemployment Rate and Its Implications for Monetary Policy [Memorandum (authorized for public release 1/11/19)]. [Online] Available:

https://www.federalreserve.gov/monetarypolicy/files/FOMC20130607memo04.pdf

Berge, T. J., Chang, A. C., \& Sinha, N. R. (2019). Evaluating the conditionality of judgmental forecasts. International Journal of Forecasting, 35(4), 1627-1635.

https://doi.org/10.1016/j.ijforecast.2019.03.026

Blau, F. D., \& Kahn, L. M. (2007). Changes in the Labor Supply Behavior of Married Women: 1980-2000. Journal of Labor Economics, 25(3), 393-438.

https://doi.org/10.1086/513416

Chalom, R., Karahan, F., Pilossoph, L., \& Topa, G. (2018, September 10). Whither Labor Force Participation? - Liberty Street Economics [Federal Reserve Bank of New York]. [Online] Available:

https://libertystreeteconomics.newyorkfed.org/2018/09/whither-labor-force-participation.html

Coglianese, J. (2018). The Rise of In-and-Outs: Declining Labor Force Participation of Prime Age Men (\&lt;em\&gt;Job Market Paper\&lt;/em\&gt;) (p. 72) [Working Paper]. Cambridge, MA: Harvard University.

Diebold, F. X., \& Mariano, R. S. (1995). Comparing Predictive Accuracy. Journal of Business \& Economic Statistics, 13(3), 253-263.

https://doi.org/10.1080/07350015.1995.10524599

Erceg, C. J., \& Levin, A. T. (2014). Labor Force Participation and Monetary Policy in the Wake of the Great Recession. Journal of Money, Credit and Banking, 46(S2), 3-49.

https://doi.org/10.1111/jmcb.12151

Faust, J., \& Wright, J. H. (2009). Comparing Greenbook and Reduced Form Forecasts Using a Large Realtime Dataset. Journal of Business \& Economic Statistics, 27(4), 468-479. https://doi.org/10.1198/jbes.2009.07214 


\section{$\triangle 1$ Macrothink}

Business and Economic Research ISSN 2162-4860 2019, Vol. 9, No. 4

Frees, E. W. (2006). Forecasting Labor Force Participation Rates. Journal of Official Statistics, 22(3), 453-485.

Fujita, S. (2014). On the Causes of Declines in the Labor Force Participation Rate (pp. 12) [Working Paper]. [Online] Available:

https://philadelphiafed.org/-/media/research-and-data/publications/research-rap/2013/on-the-c auses-of-declines-in-the-labor-force-participation-rate.pdf

Hornstein, A., \& Kudlyak, M. (2018). Aggregate Labor Force Participation and Unemployment and Demographic Trends * [Working Paper].

https://doi.org/10.2139/ssrn.3347310

Hornstein, A., Kudlyak, M., \& Mullin, J. (2019). Economic Brief, September 2019, No. 19-09-Federal Reserve Bank of Richmond (No. No. 19-09; pp. 5). [Online] Available:

https://www.richmondfed.org/publications/research/economic_brief/2019/eb_19-09

Hornstein, A., Kudlyak, M., \& Schweinert, A. (2018). The Labor Force Participation Rate Trend and Its Projections (No. 2018-25). [Online] Available:

https://www.frbsf.org/economic-research/publications/economic-letter/2018/november/us-lab or-force-participation-rate-trend-projection/

Hotchkiss, J. L. (2005). Employment Growth and Labor Force Participation: How Many Jobs Are Enough? Federal Reserve Bank of Atlanta Economic Review, 90(1), 1-13. https://doi.org/10.2139/ssrn.639662

Hotchkiss, J. L. (2006). Changes in Behavioral and Characteristic Determination of Female Labor Force Participation, 1975-2005. Federal Reserve Bank of Atlanta Economic Review, 91(2), 1-20.

Hotchkiss, J. L. (2009). Changes in the Aggregate Labor Force Participation Rate. Federal Reserve Bank of Atlanta Economic Review, 94(4), 1-6. https://doi.org/10.2139/ssrn.1433124

Hotchkiss, J. L., \& Moore, R. E. (2018). Some Like It Hot: Assessing Longer-Term Labor Market Benefits from a High-Pressure Economy. https://doi.org/10.29338/wp2018-1b

Krueger, A. B. (2017, September 7). Where have all the workers gone? An inquiry into the decline of the U.S. labor force participation rate. https://doi.org/10.1353/eca.2017.0012

Montes, J. (2018). CBO's Projection of Labor Force Participation Rates (Working Paper No. 2018-04). [Online] Available:

https://www.cbo.gov/system/files/115th-congress-2017-2018/workingpaper/53616-wp-laborf orceparticipation.pdf

Reifschneider, D., \& Tulip, P. (2019). Gauging the uncertainty of the economic outlook using historical forecasting errors: The Federal Reserve's approach. International Journal of Forecasting, 35(4), 1564-1582. https://doi.org/10.1016/j.ijforecast.2018.07.016

Robertson, J. (2019, May 6). Improving Labor Force Participation. [Online] Available: https://macroblog.typepad.com/macroblog/2019/05/improving-labor-force-participation.html 
Romer, C. D., \& Romer, D. H. (2000). Federal Reserve Information and the Behavior of Interest Rates. American Economic Review, 90(3), 429-457.

https://doi.org/10.1257/aer.90.3.429

Romer, C. D., \& Romer, D. H. (2008). The FOMC versus the Staff: Where Can Monetary Policymakers Add Value? American Economic Review, 98(2), 230-235.

https://doi.org/10.1257/aer.98.2.230

Stark, T. (2010). Realistic evaluation of real-time forecasts in the Survey of Professional Forecasters. Federal Reserve Bank of Philadelphia Research Rap Special Report, (May). [Online] Available: https://ideas.repec.org/a/fip/fedprr/y2010imayx1.html

Stock, J., \& Watson, M. (2007). Why Has U.S. Inflation Become Harder to Forecast? Journal of Money, Credit, and Banking, 39, 3-33. https://doi.org/10.1111/j.1538-4616.2007.00014.x

Terry, E. (2019, February 14). Trends in Hispanic Labor Force Participation. [Online] Available:

https://macroblog.typepad.com/macroblog/2019/02/trends-in-hispanic-labor-force-participati on.html

\section{Appendix}

Appendix 1. Comparing OASDI and EIA labor force growth projections with a random walk

Appendix Table 1.1 compares the RMSFEs from projections of the growth in the size of the labor force generated by the Old-Age and Survivors Insurance Trust Fund (OASDI) and the Energy Information Agency (EIA) with labor force growth projections generated by assuming that LFPR is generated by a random walk. ${ }^{20}$ The OASDI Trustee longer-run forecasts are perhaps slightly more accurate on average than the random-walk LFPR model, although none of the differences is statistically significant at the 90 percent confidence level according to the DM test. ${ }^{21}$

The performance of the EIA projections relative to the random walk model is mixed, though the only forecast horizons where the accuracy differences are statistically significant are ones where the random walk model performs better. Overall, there is little evidence that the EIA and OASDI Trustees projections of labor force growth are significantly more accurate than the growth projected assuming LFPR progresses as a random walk.

Annual OASDI Trustee projections of labor force growth are available in each annual OASDI Trustees Report available online: https:/www.ssa.gov/oact/TR/. We use the "intermediate assumptions" projections of labor force growth as opposed to the "low-cost" and "high-cost" alternatives. EIA projections of the labor force size are available in excel files accompanying the Annual Energy Outlook (AEO). The AEO was typically released early in the year until 2008. Since then, there has usually been an "early release" version of the AEO that includes projections of the labor force. In our forecast evaluation, we use forecasts from the "early releases" after 2007 whenever they are available. These two groups release forecasts for the

\footnotetext{
20 This essentially amounts to assuming that the labor force grows at the same rate as the population.

21 The differences are also not statistically significant when the labor force growth forecasts are cumulated.
} 
current and subsequent 20+ years.

In order to make the comparisons found in Appendix Table 1.1, certain assumptions are required. Assuming that the LFPR progresses as a random walk is the same as assuming that the size of the labor force grows at the same rate as population growth. Additionally, we need to assume that the resident population will grow at the same rate as the civilian non-institutional population. Since 2001, the annual growth rate of the resident population has differed from the annual growth rate of the civilian non-institutional population by no more than 0.05 percentage points.

Appendix Table 1.1. Root-mean square forecast errors of annual labor force growth (percentage points)

\begin{tabular}{|l|l|l|}
\hline \multicolumn{3}{|c|}{ Forecasts from 1994 - 2017 OASDI Trustee Reports } \\
\hline & OASDI Trustees & LFPR Random Walk model \\
\hline 1-year ahead & 0.451 & 0.451 \\
\hline 2-year ahead & 0.492 & 0.471 \\
\hline 3-year ahead & 0.484 & 0.467 \\
\hline 4-year ahead & 0.430 & 0.436 \\
\hline 5-year ahead & 0.402 & 0.429 \\
\hline Forecasts from 1996 - 2017 EIA Annual Energy Outlook \\
\hline & EIA & LFPR Random Walk model \\
\hline 1-year ahead & 0.436 & 0.482 \\
\hline 2-year ahead & 0.534 & $0.479^{*}$ \\
\hline 3-year ahead & 0.512 & $0.467^{*}$ \\
\hline 4-year ahead & 0.489 & 0.469 \\
\hline 5-year ahead & 0.446 & 0.463 \\
\hline
\end{tabular}

Notes: Forecasts from 1997 Annual Energy Outlook not included due to lack of online availability. * => Significant improvement from EIA forecast in forecast accuracy at the 90 percent confidence threshold.

For population growth, we use real-time U.S. Census Bureau projections of the resident population ages 16 years and older. ${ }^{22}$ The Census Bureau forecasts the size of the July 1 st population for each of its projection years. We treat these as forecasts of the July population size and linearly interpolate the logs of the July levels. Jumping off from the size of the labor force in the most recent employment report that was available at the time of the EIA or OASDI Trustees forecast, we assume that the labor force grows at the same rate as the interpolated Census population projection in every subsequent month in the current and subsequent five calendar years.

Evaluating the accuracy of the EIA and OASDI Trustees forecasts is complicated by level shifts in the size of the labor force that occur when the Bureau of Labor Statistics incorporates updated population controls from a decennial census or the American Community Survey. To mitigate these breaks, we set the "actual" monthly labor force series to its estimate from the most recent employment report available to the EIA or OASDI

\footnotetext{
22 Available at https://www.census.gov/programs-surveys/popproj.html and https://www.census.gov/prod/www/population.html
} 


\section{Macrothink Institute ${ }^{\mathrm{TM}}$}

Trustees and extend it using the monthly growth rates of the March 2019 vintage of the BLS's labor force research series smoothed for population control adjustments. ${ }^{23}$

A number of other government agencies and private organizations make regular, typically annual, projections of the growth in the size of the labor force. The BLS often releases 10-year ahead and, sometimes, annual forecasts of the labor force and labor force participation rate. ${ }^{24}$ Evaluation of these 10-year BLS projections are available at Byun et al. (2015) and Bureau of Labor Statistics (2018). These studies found that the BLS substantially over-predicted labor force growth and/or LFPR, but generally forecasted labor force growth or the participation rate as well or, in some cases, better than a naïve model extrapolating the most recent 10-year trend. ${ }^{25}$ The Congressional Budget Office also forecasts the labor force and/or the labor force participation rate at least once a year. However, sufficiently lengthy continuous time series of these forecasts on an annual basis are not readily available.

Appendix 2. Coefficients estimated each year versus all years together, youth and elderly.

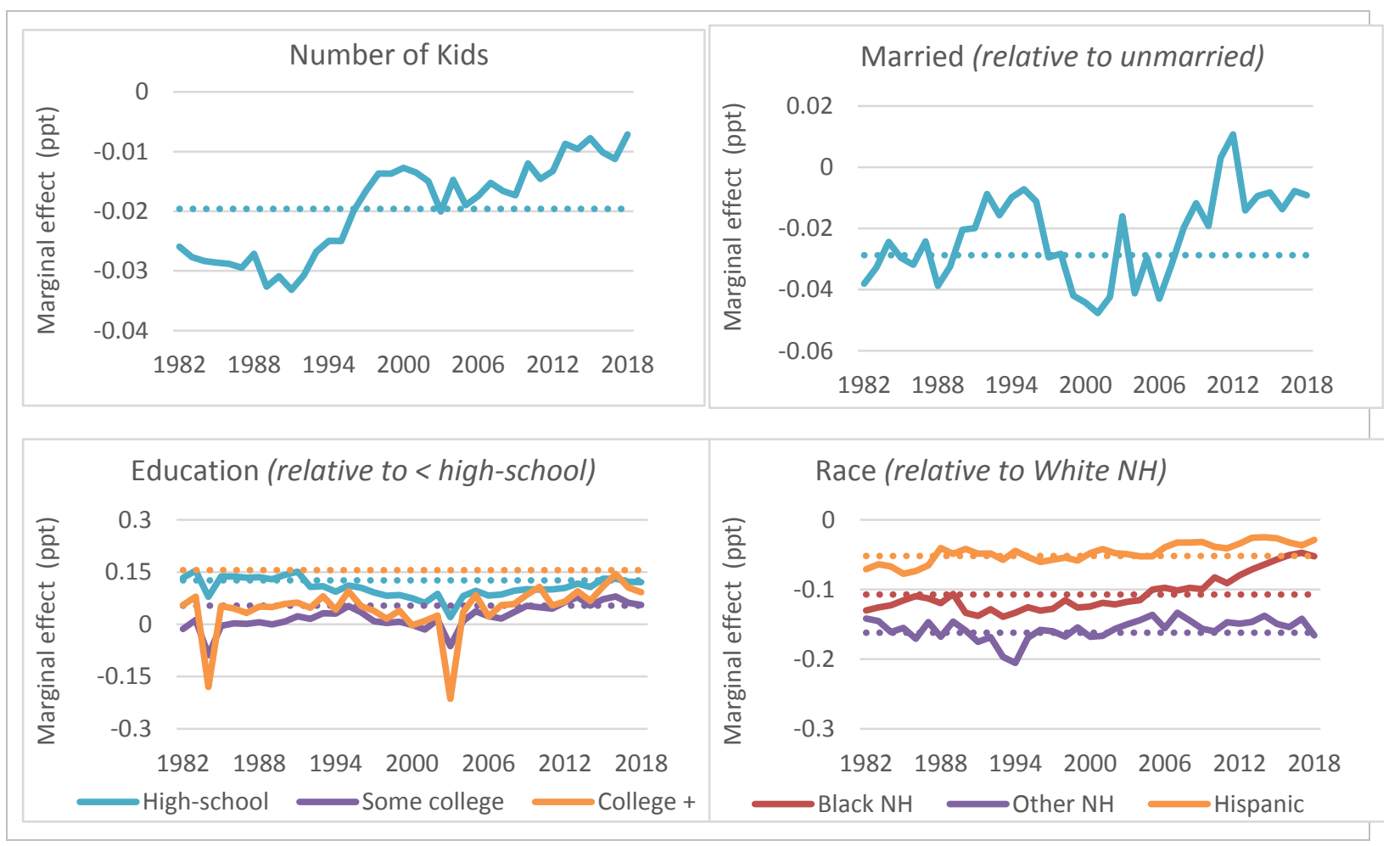

\footnotetext{
23 Available at https://www.bls.gov/cps/smoothed_lf.xlsx. Since it is not always clear which vintage of the monthly employment report was the one the EIA or the OASDI Trustees consulted when forming their labor force projections, we do not evaluate the accuracy of the current-year labor force growth projections. Although OASDI Trustee projections are available online since 1990, we only include forecasts made after 1993 so that the results are not distorted by the impact of the January 1994 CPS redesign on the labor force participation rate. ${ }^{24}$ See the references cited at https://www.bls.gov/emp/publications/projections-overview.htm.

25 Evaluating the BLS overprediction of 5-year ahead LFPR made in 2007, Erceg \& Levin (2014) found that much of the forecast error was concentrated overpredicting the participation rates of younger (16-24 years) and prime-age (25-54 years) age groups.
} 

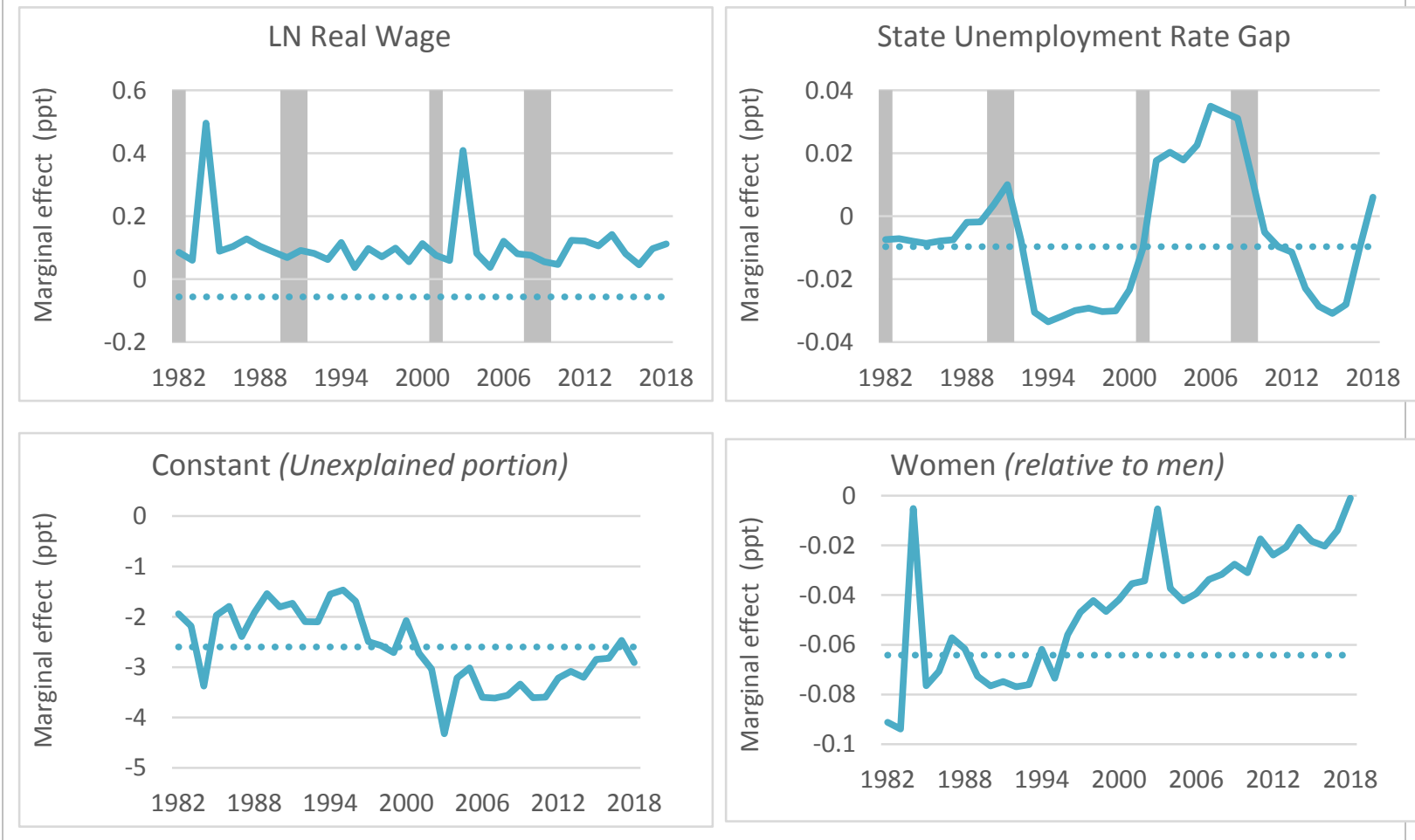

Appendix Figure 2.1. 16-24 Year olds

Notes: Dotted lines are coefficients estimated using all data 1982 and 2018 together. Solid lines reflect coefficients for model estimated on single years of data. Coefficients for age and age squared are not shown.

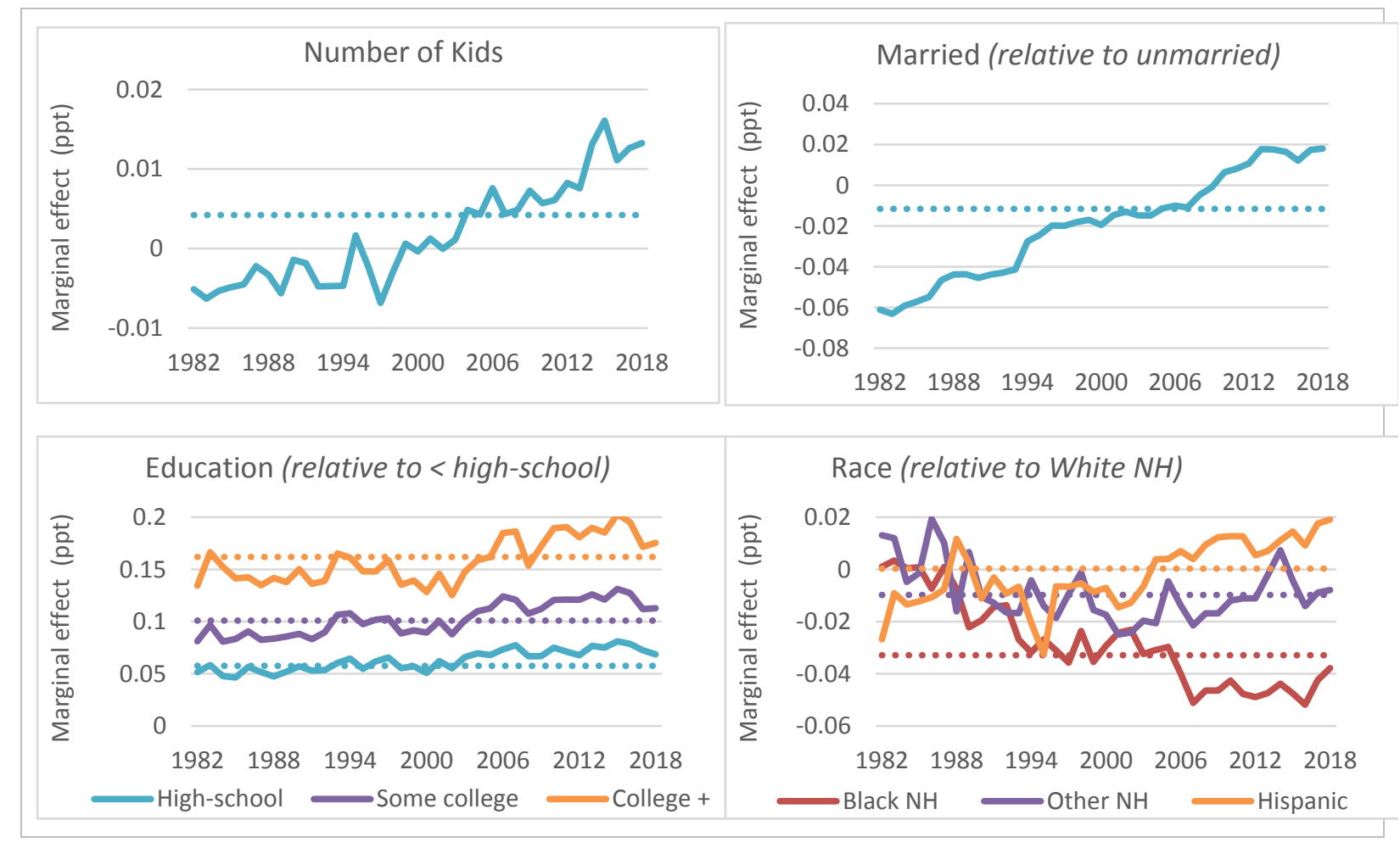



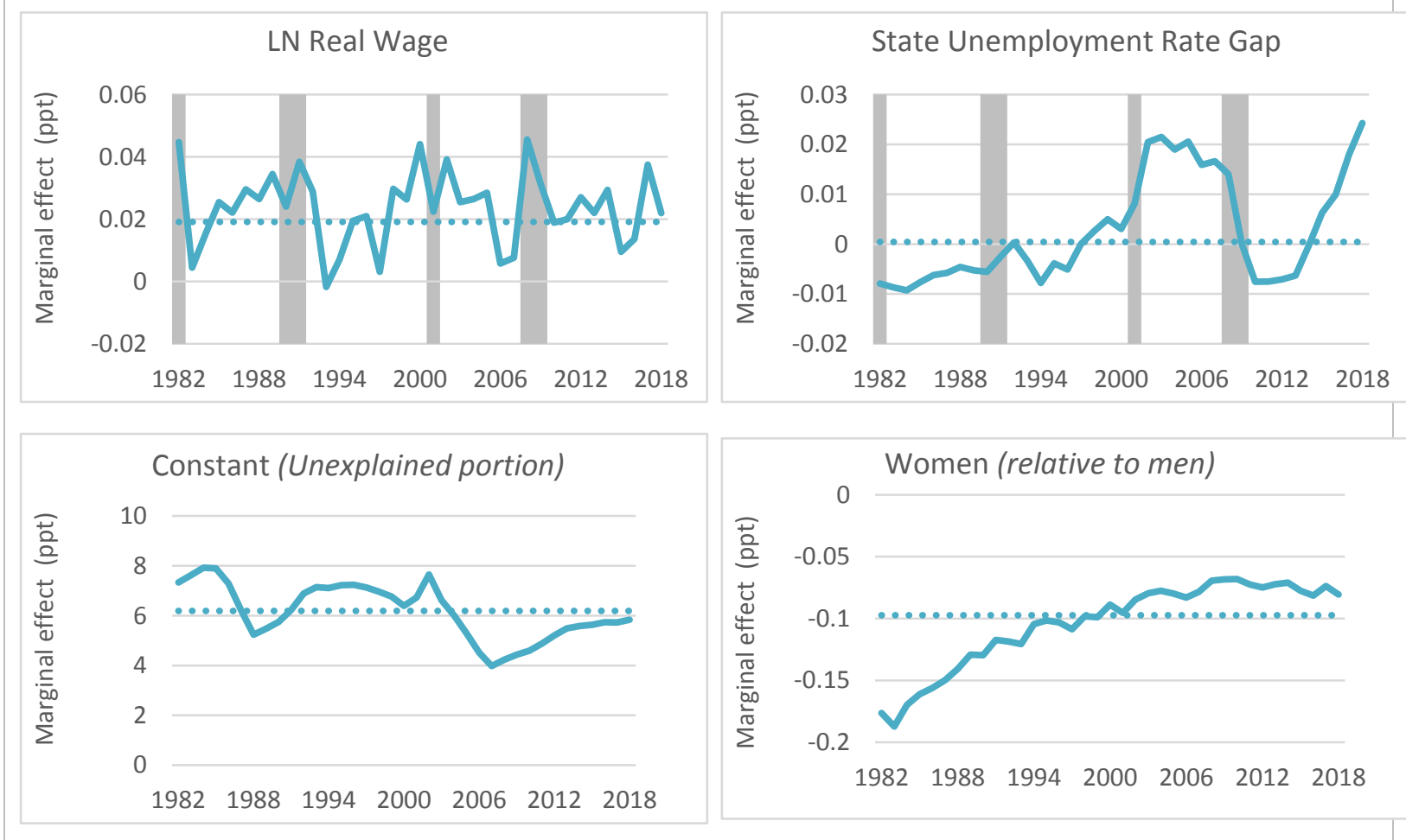

Appendix Figure 2.2. 55+Year olds.

Notes: Dotted lines are coefficients estimated using all data 1982 and 2018 together. Solid lines reflect coefficients for model estimated on single years of data. Coefficients for age and age squared are not shown.

\section{Copyright Disclaimer}

Copyright for this article is retained by the author(s), with first publication rights granted to the journal.

This is an open-access article distributed under the terms and conditions of the Creative Commons Attribution license (http://creativecommons.org/licenses/by/3.0/). 